\title{
A review of factors affecting the success of membrane protein crystallization using bicelles
}

\author{
Ann C. Kimble-Hill \\ Dept. of Biochemistry and Molecular Biology \\ Indiana University School of Medicine \\ 635 Barnhill Dr., Indianapolis, IN 46202-5126. \\ Tel.: 317-278-2009; Fax: 317-274-4686; E-mail: ankimble@iupui.edu.
}

\begin{abstract}
Several reports have been published detailing various platforms for obtaining crystals of membrane proteins to determine their structure including those that use disk shaped bilayers called bicelles. While these crystals have been readily grown and used for x-ray diffraction, the general understanding as to why bicelles are adequate for such a procedure or how to rationally choose conditions remains unknown. This review intends to discuss issues of protein stabilization and precipitation in the presence of lipids that may influence crystal formation.
\end{abstract}

Keywords: bicelle, membrane protein, crystallization

This is the author's manuscript of the article published in final edited form as:

Kimble-Hill AC. A review of factors affecting the success of membrane protein crystallization using bicelles. Front Biol. 2013 Jun 1;8(3):261-72. Available from: http://dx.doi.org/10.1007/s11515-012-1208-0 


\section{Introduction}

Approximately one-third of the genome is dedicated to membrane proteins but there are few unique atomically resolved membrane protein structures compared to those of soluble proteins (over 30,000 structures for soluble proteins versus approximately a 100 -fold decrease for membrane proteins), illustrating that obtaining membrane protein crystals continues to be a significant challenge (1). These statistics alone demonstrate the importance to finding mechanisms to obtain structural information on these proteins in order to understand their activity within the membranes of living cells. However, such information is scarce, to great extent, due to their amphiphilic character, which is critical to their function within the cellular membrane.

Membranes are made up of bi-layered lipids forming an essentially impermeable barrier, whose functionality is mediated by a myriad of membrane proteins, including those that span the transmembrane region $(2 ; 3)$. Structural information on membrane proteins is needed to understand how these proteins behave within the membranes of living cells. The lipid environment around membrane proteins has been proposed to directly influence protein functionality. For example, the surrounding lipids affect membrane protein structure and function by causing tilting, bending and/or by decreasing the height of the transmembrane helices or they can reorganize and/or swell around a protein (4-6). Such conformational changes have been associated with changes in affinity for regions differing in lipid composition within the membrane. Thus, obtaining the structures of membrane proteins in different lipid environments and binding conditions will ultimately be critical for relating structural changes to signaling events. This knowledge will then help develop those biotechnologies that produce drug therapies targeting specificity in protein functionality.

Atomically resolved membrane protein structures are obtained with high quality protein crystals for x-ray diffraction measurements. Currently, the most common membrane protein crystallization procedure is a pure surfactant method (7), whereby membrane proteins are removed from their native environment by detergents and then induced to nucleate into crystals that contain both proteins and detergents. Although successful, 
detergent stabilization of hydrophobic moieties of these proteins has been very challenging. Detergents that are generally successful in removing proteins from membranes do not stabilize protein structure for long periods of time, and therefore are not successful in crystallization trials (8). Micellar/cubic phase crystallization also has its challenges in that micelles co-exist with protein-detergent aggregates that form when the detergents are above the critical micelle concentration (CMC), a condition often necessary to pull the proteins from the lipids. Above detergent CMC, detergents undergo micellar phase transitions and fuse into macromolecular structures and the detergent itself can form a physical barrier or detergent ring preventing protein-protein interactions (914). In addition, some detergents will phase separate at high precipitant concentrations and form birefringent liquid crystal phases (7).

Recently some membrane proteins have been crystallized in solutions of amphiphilic molecules that form bicontinuous membrane-mimetic phases $(6 ; 15 ; 16)$. These mixtures serve as adequate environments for membrane protein crystallization as they form an interconnected membranous environment in which several proteins can be reconstituted and structure stabilized. This environment becomes a lipid scaffold allowing proteins to freely diffuse and form nucleation sites. Currently there are two bicontinous mixture types in which crystallization has consistently worked: the bicontinuous cubic phase and the bicelle lipid mixture solution (6; 15). There are approximately thirty structures deposited with the Protein Data Bank that were resolved from lipidic cubic crystals, where there are some 14 structures resolved using bicelles that have been deposited. In cubic crystallization, the temperature is increased to at least $20^{\circ} \mathrm{C}$ where with the help of the precipitant, the continuous bulk cubic phase bilayer contracts and curves to induce protein association and organization into a crystal lattice (17). In general, bicontinuous cubic phase preparations that are best found to yield crystals contained $60-70 \%(\mathrm{wt} / \mathrm{wt})$ monoolein or monopalmitolein as well as small amounts (1.2\% wt/wt) of a detergent such as octylglucoside (Landau 1996). Small angle x-ray scattering shows that crystal volume per unit protein mass of cubic grown crystals is larger, and therefore denser in packing, than those grown in with bicelles or other bilayered systems (18). However, the lipid cubic phase has proven to be difficult to work with due to its viscous nature whereas bicelles are liquids that can easily be manipulated and used for crystallization at much 
lower temperatures (19). Bicelles are a disk-shaped long-chain phospholipid bilayer (e.g. DMPC) capped by short-chain phospholipids (e.g. DHPC, CHAPSO) whose diameter is determined by ratio of long-to-short chain lipids, q, and thickness driven by the length of the long-chain lipid acyl chains (20-23). As the temperature and concentration is moderately increased the structure is better described as being worm-like or ribbon nematic transition, where the small discoidal micelles have joined together to form a mostly continuous ribbon structure where the short chain lipid is segregated to the structural edge $(23 ; 24)$. Further increases in temperature and concentration causes lengthening to a more perforated lamellar phase, driven by the immiscibility of DMPC and DHPC above DHPC’s, yet below DMPC’s, melting temperature where DHPC forms holes in the bilayer (Figure 1) $(24 ; 25)$.

As of December 2011, there were 15 unique x-ray crystallography structures for membrane proteins deposited in the Protein Data Bank generated from crystals grown in the lipid cubic phase while the structures resolved by x-ray crystallography using bicelles have been those of the rhodopsin family, human $\beta 2$-adrenergic G-protein couple receptor, voltage-dependent anion channel 1, and rhomboid protease (19; 22; 26-29) (Table 4). There were also 6 unique bicelle related structures deposited using NMR, suggesting that this method is of greater value for structural biologists. This report is intended to review what is currently known about the effect of common crystallization lyotropes and precipitants on lipid systems, leading to a design rationale for future crystallization of membrane proteins using bicelles.

\section{Discussion}

Protein crystallization is described as a process of three stages: nucleation, growth of nuclei into mature crystals, and termination of crystal growth (30). Generally, the nucleation can be linear or branched oligomers where growth can be in one of two dimensions or the protein may oligerimize in into all three directions (31). In the case of membrane proteins which intercolate a lipid environment, nucleation is a results of 2D contacts within the membrane, and the third dimension is a result of interaction of proteins within membranous stacks (Type I). Alternatively, the hydrophilic surface of the membrane extending from a micelle serves as potential sites for crystal contacts in detergent solubilized proteins (Type II). Lamellar protein crystallization, such as 
biclles, extends from Type I crystals, lending to a thinner crystal but with more controlled growth than a Type II crystal (32). The effect of crystallizing the hallmark protein Bacteriorhodopsin in these different crystal packing types has been described in Table 3. For this protein, Type I crystals have led to higher resolution structures, and bicelle associated structures are much more symmetrical, providing motivation for further investigation of bicelle crystallization for other proteins. Oligermization into all three directions is generally responsible for driving nucleation into the growth of a stable crystal, and the degree of protein supersaturation determines the rate of crystal growth. Crystallographers have often used precipitants as a mechanism to drive the condition of supersaturation. Those additives include: salts, detergents from purification/stabilization of the protein, and polyethylene glycol. Too rapid of crystal growth has been associated with defects in crystal formation, as described by decrease in order, increased mosaicity, misaligned unit cells, and increased incorporation of impurities. These defects lead to crystals that do not diffract well and problematic diffraction analysis (31). Therefore, bicelles as the hydrophobic shield provides a better balance for controlled growth during supersaturation than detergent based methods. These additives can also affect the behavior of the lipids and drive the formation of lipid structures that enhance the ability to crystallize membrane proteins. To rationally design bicelle crystallization conditions, all of these factors should be accounted for and are described in this review.

Proteo-bicelle Crystallization. The methodology of protein crystallization using bicelles as the membranous environment to stabilize the hydrophobic transmembrane regions of the protein has been previously described in great detail (19; 33-35). In this method, detergent stabilized membrane proteins are mixed with bicellar mixtures, a low pH but high salt precipitating solution, and a small amount of an alkyl glycoside detergent. Crystals are then grown using the hanging drop or sitting drop methods at room temperature or higher. While the general structure of the bicelle has been described in these conditions, there are many additives that are used during the crystallization of proteins that can affect the bicelle lipid, thereby affecting the precipitating conditions that should be used for crystallization. The perturbations can be seen in lipid melting temperature, which affects 2D protein diffusion for the initial nucleation events, and lamellar stacking/rippling which support 
crystal growth in the third dimension. In general, 2D diffusion of proteins in lamellar structures is faster with more possibilities for collisions associated with nucleation events in fluid rather than gel state lipids (36; 37). Decreases in the lamellar spacing increases the probability of interfacial protein contacts which should also support crystal growth.

Long-Chain Lipids. Several bicelle mixtures have been described which use several lipid types as the long chain lipid, including phosphatidylcholine (PC), phosphatidylethanolamine (PE), phosphatidylserine (PS), and Phosphatidylglycerol (PG). Each of these phospholipids has two different characteristics to be considered when incorporating into a bicelle: shape and head-group charge. Lipid shape influences the overall shape of the bicelle as they elongate as well as change the melting temperature. The shapes of PC, PS, and PG lipids lend to a preference for forming lamellar liquid crystalline phases, however PE lipids form the inverted hexagonal phase (Table 2) (38; 39). The bicellar lamellar interior at low temperatures that extend into perforated lamellar repeating units with increasing temperature is driven by the presence of lamellar phase lipids (24; 40). PC and PE have zwitterion head groups, while PS and PG head groups have a negative charge at most relevant PHs. Charge on the surface of the bilayer due to ions present in the buffer solution can affect its ability to interact with proteins by either repelling or attracting the protein to the membrane. However, this charge can manipulate the bulk buffer as well as the phase transition of the bilayer. Gouy-Chapman boundary layer affects have been discussed at length elsewhere (41-43). In short, the presence of anionic lipids creates localized charge build-up that becomes dispersed with respect to the distance from the surface of the membrane. Charge in the buffer has also been shown to affect the structure of the bicelle. Cations have been shown to increase the diameter of PC containing bicelles proportional to ion charge (44). In addition, the melting temperature of the lipid is sensitive to $\mathrm{pH}$ which affect the ionization state of the head group as demonstrated by the ability of divalent cations to increase, and monovalent cations to decrease, the melting temperature of negatively charged bilayers (45). Anion groups larger than chlorides, such as sulfates and acetates, bind more tightly to PC headroups and cause a decrease in phase transition temperature (46; 47). In PC lipids, the temperature range for the discoidal shape is extended by the presence of monovalent salts, which suggests an effect opposing anions on zwitterionic lipids 
(48). Therefore the presence of ions can be used to modulate and stabilize the fluidity and phase of the bicelle during crystallization, in addition to precipitating and stabilizing the protein.

Not only have additives shown to affect the melting temperatures of the lipids, they also affect lamellar spacing which in turn determines the ability of proteins to form the contacts in the third dimension. As the concentration of ions in solution increases, zwitterionic head groups experience a decrease in repulsive hydrations and attractive van der Waals forces (49). Monovalent cations increase size of the water layer in between bilayers (46), but generally have less of an effect than that of divalent cations whose effects are seen even with very low concentrations (50-53). Increasing concentrations of monovalent salts such as potassium chloride and potassium bromide have a sigmoidal salt-induced swelling effect on the lamellar systems (54). Petrache et al. have shown that this effect is more significant at low osmotic pressure, as DLPC multilayers swell to a maximum which is specific to the counterbalancing anion. While salts are generally used to cause supersaturation of the protein, one must keep in mind that the presence of salts will cause an increase in the water layer within lamellar stacks thereby decreasing the amount of potential contacts during nucleation and crystal growth. Evaporation is generally key in moving the protein solution from nucleation to the growth of crystals. However, in the case of proteo-bicelle crystallization, evaporation may terminate crystal growth as the bilayers move farther apart in response to the increasing local salt concentration.

Membranes and Alkyl Glycosides (AGs). Detergents such as n-octyl- $\beta$-D-glucoside (OG) and dodecyl maltoside (DM) belongs to a larger class of non-ionic surfactants, AGs, which contain one or several glucose molecules in the hydrophilic part, and at least one hydrocarbon chain that makes up the hydrophobic part. These detergents have been used during solubilization of native membranes to stabilize purified membrane proteins. Sucrose density gradient centrifugation studies have shown that in general, membrane proteins that behave as monomers or dimers bind between 0.28 and 1.12g of detergent per g of protein (55). That report, in addition to thin layer chromatography work, suggests that after reconstituting proteins into bicelles in the aforementioned proteobicelle crystallization methods the mixtures would contain 7-30 mg/ml of OG. The addition of AG detergents at 
these amounts to the mixtures demands that attention be paid to the structure of the detergents themselves as well as the effect of this detergent type on membranous structure.

Studies in aqueous buffers show that as the concentration increases to the critical micelle concentration, aggregates of these molecules have a self-induced curvature, forming an isotropic spherical or oblate ellipsoidshaped micelle (56; 57). Small angle neutron scattering shows that the structure of the OG micelle is ellipsoidal, where the long axis increases in length as the concentration of the molecule increases from the CMC to 292 $\mathrm{mg} / \mathrm{ml}$ (58) creating a more rod-like or cylindrical micelle. As the concentration of this detergent increases, the molecules condense and organize to form higher ordered and more continuous phases including hexagonal, followed by cubic structures at room temperature. As the concentration further increases, a lamellar phase is seen (59). In the current crystallization methodology being studied, the concentration of this lyotrope would begin in the fluid isotropic regime, where micellar ellipsoids prevail growing with increasing lyotrope concentration along the long axis to a more rod-like shape, which is opposite that of the typical discoidal growth demonstrated with phospholipids generally used in bicelle mixtures.

The additive effect of the presence of these detergent micelles on membranes has been studied using two different lipid phases: lamellar and bicontinuous cubic phase, where long chain PC lipids and monoolein (MO) are used, respectively. As OG is added to cubic MO (Qiu, 2000), the OG incorporates homogenously within the membrane moving the structure from a continuous packing of membranous blocks to a lamellar stacking of fluid membranous sheets. Similarly, when OG was added to a lamellar phase formed by DPPC, it also changed the phase from the viscoelastic gel to a fluid $\mathrm{L}_{\alpha}$ lamellar phase generally only seen by DPPC at temperatures above its melting point (60). Other reports have showed that lamellar liposomes created from egg phosphatidyl choline and egg phosphatidic acid become solubilized by less than $10 \mathrm{mg} / \mathrm{ml} \mathrm{DM}$ in solution (61; 62) and POPC vesicles were solubilized with alkyl ether with similar characteristics as decylmaltoside, where an increase in detergent composition moves the solution from a lamellar phase to a mixed micelle cubic phase (63; 64). Lipidic studies done in lamellar phases, suggest that an addition of OG to bicelles would induce the solubilization of the membrane into micelles. Hence, it stands to reason that in the case of the proteo-bicelle 
crystallization procedure, the bicelle solution will change from ribbon-like lamellar structure to a cubic and/or micelle structure with the addition of OG, with the final structure being temperature and total lyotrope concentration dependent. Due to the significant amount of detergent present in the proteo-bicelle crystallization, as was seen in the micellar and lipid cubic methods, it becomes important to understand the structural changes driven by the presence of the detergent OG. My previous work presented at several conferences suggests that bicelle structure also changes as a function of OG/DM content, temperature, and total lyotrope concentration using small angle neutron scattering (SANS) measurements (65). Bicelle mixtures with less than 20\% detergent and greater than $30 \mathrm{mg} / \mathrm{ml}$ lipid have structures characteristic of an elongated bicelle, which becomes lamellar as the temperatures increases (unpublished). As seen with lamellar mixtures, an increase in the detergent content leads to a biphasic regime where the bicelle takes on the rod characteristic of the detergent (unpublished) (Figure 2). Elongating bicelles with low amount of OG to crystallize membrane proteins as reported by Faham et al., as well as other groups, serves as a mechanism to increase the number of proteins in each aggregate thereby increasing the possibility of protein nucleation events (19). Further increasing the temperature of these elongated structures could also provide a stacking of the aggregates, furnishing a means for proteins from various aggregates to form even larger crystals. In addition, as these detergents incorporate throughout the bilayer region of the bicelle, they contribute to the thickness of the membrane. Thinning of the DMPC bilayer by OG may allow for the membrane to better match the hydrophobic moieties of the protein's transmembrane structure. Mouritsen et al. proposes a macroscopic mattress model in which lipids of the membrane must entirely wet, or hide, this region in order to maintain protein structure, or risk deforming either the protein or the surrounding local membrane (4; 66). However, Dumas et al. suggest that Bacteriorhodopsin (Br) has a higher affinity to long chain DSPC (18:0 PC) than short-chain DPPC (16:0 PC) at temperatures higher an $40^{\circ} \mathrm{C}(67)$. A potential resolution to the discrepancy between these studies may be found in addressing the affects of detergents on membrane fluidity. The study by Dumas was done above the melting temperature of these lipids suggesting that both lamellar structures were liquids instead of viscous gels, whereas pure bicelle mixtures at high concentrations and temperatures lower than $40^{\circ} \mathrm{C}$ (the conditions used by Faham et al.) have been 
characterized to be viscous gel-like lamellar phases. The addition of small amounts of OG results in a less viscous mixture, which would reduce the temperature needed to "melt" the lipids.

Like salts, detergents also affect the d-spacing of the lamellar phase however the effect is head group and acyl chain dependent. The addition of OG to DPPC and DOPE bilayers lead to a decrease in d-spacing, however detergents such as dodecyl sulfate are expected to increase the lamellar spacing (60; 68). OG decreases the inter-lamellar spacing of DOPE bilayers with increasing temperature, while increasing DPPC inter-lamellar spacing (60). DM had little effect, while dodecyl- $\beta$-d-glucopyranoside (DG) increased the spacing of DPPC lamellar structures at room temperature. As the temperature increases, the DPPC-DG and DPPC-DG mixtures are able to compensate for the loss of hydration and returns the d-spacing to that of the native DPPC bilayer or even tighter packing (69). When taken in the context of proteo-bicelle crystallization, the effect of room temperature OG and high temperature DM/DG on lamellar stacking should lead to an increase in nucleation contacts and crystal growth. However, care should be taken to the final concentration of any of these detergents in the final crystallization conditions.

Polyethylene Glycol (PEG). Bicelle crystallization has been used successfully at two different temperatures. The first publication of bacteriorhodopsin (bR) crystals using this method was at $37^{\circ} \mathrm{C}$ using (3:1) DMPC/CHAPSO bicellar solution to create a mixture of $-8.0 \mathrm{mg} / \mathrm{ml} \mathrm{bR} / 8 \%$ bicelles mixture which was precipitated by 3.2 $\mathrm{M} \mathrm{NaPO}_{4}$ (pH 3.5) (22). Similar crystals were also formed using DMPC/CHAPSO bicelles at room temperature by introducing $180 \mathrm{mM}$ hexanediol with either 30\% PEG2K or 3\% triethylene glycol (19). Low molecular weight PEG (e.g. PEG400) have been shown to increase the transition temperature of phospholipids, however PEGs with molecular weights greater than $1 \mathrm{~K}$ have been shown to drive a depletion effect that leads to aggregation and lateral fusion of lamellar membranes (70-72). Faham et al. used this lamellar fusion effect of PEG2K to reduce the melting temperature of this bicellar mixture, which transitioned the bicelle into the perforated lamellar phase to crystallize bR at room temperature (Table 3). The change in lipid melting temperature associated with the presence of PEG has also been linked to the hydration state, and therefore the lamellar spacing of PC, PS, and PE bilayers (73). PEG has been shown to wrinkle or form large 
bumps in the lamellar and hexagonal structures (73-76). In addition to the wrinkles, it decreases the interfacial spacing of these lipid structures and this effect is intensified with increasing temperature (75). Rippling and decreases in d-spacing in the perforated lamellar structure generated by PEG in proteo-bicelle crystallization can only serve to increase the nucleation events and promote crystal growth.

Acyl Chains. Generally, bicelles are made with aliphatic long chain lipids between 12 and 18 carbons in length (21). A summary of some common long chain phospholipids used in bicelle mixtures and their properties can be found in Table 1 (77-81). Lipid-detergent mixtures close to phase separation boundaries should be avoided if unnecessary as it has also been reported that lipid-protein interactions can also cause local compositional demixing of multiple lipid species, further inducing lipid phase separation and creating microdomains (82-85). In this case, the proteins induce a more distinct boundary condition on the thermally equilibrated binary lipid mixture in the fluid phase, and reorganization occurs via long-range diffusional processes. Phase separating lipid mixtures have been used in bicelles to mimic lipid rafts seen in cellular membranes, but their effect on structure has not yet been shown and generally should include cholesterol to stabilize the bicelle structure over a large temperature range (20). Hence, when choosing the long chain lipids for the bicelle mixture it becomes important to consider the approximate length of the membrane inserting region of the protein, overall shape/lipidic phase, charge, and melting temperature.

Hydrophobic mismatch. Mouritsen et al. suggest that for proteins to be stable in their environment, the length of the protein's hydrophobic region must match that of the hydrophobic bilayer. They also suggest that the mismatch of protein transmembrane region's height to the thickness of the bilayer's hydrophobic core may determine protein aggregation within phases depending on the strength of the van der Waals lipid-protein hydrophobic contact (4). Based on this theory, longer proteins would induce stronger lipid-mediated attractive protein-protein interactions and thereby cause aggregation. Theoretical studies have been done which show that in the presence of a transmembrane protein, the bilayer thickness increases exponentially to match the hydrophobic length of the static protein (86-91). Changes in bicelle thickness would therefore change the melting temperature, causing a shift in the temperature necessary for forming the lamellar stacks associated with 
crystallization. Therefore it becomes important to select bicelle and detergent components with long chain components most entropically favorable to interact with the hydrophobic surface of the protein without deforming the bilayer. Individual protein helices were found to experience a tilt, and more interestingly, changes in tilt angle of the individual helices were associated with changes in protein activity (5). More specifically, long, single-spanning proteins bend to adapt to a too-thin bilayer, while larger, multi-spanning proteins have small amounts of tilting (92-97). When smaller sized proteins were introduced to a hydrophobic mismatch, it induced changes of the tilt-angle of individual helices based on the conformations allowed by the protein’s activity (98). While it is not currently known if hydrophobic mismatch derived changes in the protein structure are associated with increasing the propensity to crystallize in the bicelle, it should be understood that the defects will be propagated into the protein structure.

It has been suggested that perturbations of the membrane on the macroscopic scale lead to two different kinds of mismatch adjustments. First, tilting of the protein may occur to minimize water exposure to hydrophobic regions. Second, larger proteins are able to reduce hydrophobic mismatch by deforming the bilayer rather than undergo tilting (5). To further understand this building hydrophobic mismatch theory, Sabra et al. (6) used rhodopsin, a protein noted for an affinity for fluid lipid phases, in two different states that have different hydrophobic lengths. They found that this protein was sensitive to certain types of lipids and was capable of adapting to the lipid-protein interface during the transition by adjusting the height of the transmembrane region. In general, Br has been crystallized in bicelles with DMPC, a phospholipid with 14 carbon acyl chains which is known to create a fluid phase bilayer (99). In addition, the presence of the detergent OG would increase the ability of the membrane to bend to the rhodopsin helices while minimizing the bending of the B helix to 20 degrees (100). While lipids have not been seen in the resolved structures of $\mathrm{Br}$, they have been seen in other protein structures solved using proteo-bicelle crystallization. Rhomboid protease GlpG shows small changes with respect to the detergent based structure in its L1 domain as a result of accommodating the lipid molecules, while Histindine displacements are more pronounced in the detergent versus the lipid environment (29). In addition, the structure shows that the acyl chains of the lipid are incorporated into the protein's grooves and 
crevices, allowing hydrophobic contacts between the lipid molecules and the WR motif, as well as hydrogen bonding between the lipid glycerol back bone and charged side chain amino acids (29). It has also been proposed that GlpG and the voltage-gated potassium channel thin the surrounding bilayer to accommodate their 2D oligomeric arrangements while still providing a third dimension of contact for crystal formation (29; 101; 102).

Summary. Proteins are generally crystallized using salts and PEG to drive nucleation and crystal growth. Protein domains that insert and/or pass thru their native membrane require an amphiphilic molecule to stabilize their structure. Bicelles have been used in this capacity to stabilize membrane proteins for several structure methods including x-ray crystallography. Different lipids can be incorporated into the bicelle mixture to change the bilayer thickness, lipid de-mixing, phase transition temperature, local charge build-up to induce specific lipidprotein interactions based on acyl chain length and phospholipid head group. However, the bicelle lipids are affected by salts, detergents, and PEG causing shifts in lipid melting temperature, bicelle phase, and lamellar stacking as demonstrated by the ability to use long chain PEG to achieve lamellar protein crystallization at room temperature (103). Membrane proteins participate in a variety of signaling pathways, and structure-function analysis gives way for a detailed understanding of how to modulate their function within various disease states. Structural biologists and biochemists should use these factors to improve their success with bicelle crystallization for membrane proteins.

Acknowledgements: This work was supported, in whole or in part, by National Institutes of Health Grants R01-AA018123-S1 and Department of Energy Funding FWP 58701. 


\section{References}

1. Carpenter, E. P., Beis, K., Cameron, A. D., \& Iwata, S. (2008). Overcoming the Challenges of Membrane Protein Crystallography. Current Opinion in Structural Biology, 18(5): 581-586.

2. Lodish, H., Berk, A., Matsudaira, P., Kaiser, C., Krieger, M., Scott, M., et al. (2004). Molecular Cell Biology (5th ed.). New York: Freeman Press,

3. Branden, C., \& Tooze, J. (1999). Introduction to Protein Structure. New York Garland Publisher,

4. Mouritsen, O. G., \& Bloom, M. (1993). Models of Lipid-Protein Interactions in Membranes. Annual Review of Biophysics and Biomolecular Structure, 22: 145-171.

5. Venturoli, M., Smit, B., \& Sperotto, M. M. (2005). Simulation Studies of Protein-Induced Bilayer Deformations, and Lipid-Induced Protein Tilting, on a Mesoscopic Model for Lipid Bilayers with Embedded Proteins. Biophys J, 88(3): 1778-1798.

6. Sabra, M. C., \& Mouritsen, O. G. (1998). Steady-State Compartmentalization of Lipid Membranes by Active Proteins. Biophys J, 74(2): 745-752.

7. Garavito, R. M., Picot, D., \& Loll, P. J. (1996). Strategies for Crystallizing Membrane Proteins. J Bioenerg Biomem, 28(1): 13-27.

8. Santonicola, M. G. L., Lenhoff, A. M., \& Kaler, E. W. (2008). Binding of Alkyl Polyglucoside Surfactants to Bacteriorhodopsin and Its Relation to Protein Stability. Biophys. J., 94: 3647-3658.

9. Kühlbrandt, W., Auer, M., \& Scarborough, G. A. (1998). Structure of the P-Type Atpases. Current Opinion in Structural Biology, 8(4): 510-516.

10. Garavito, R. M., \& Picot, D. (1990). The Art of Crystallizing Membrane Proteins. Methods, 1(1): 57-69. 11. Kwan, C.-C., \& Rosen, M. (1978). The Relationship of Structure to Properties in Surfactants: Vii. Synthesis and Properties of Some Sodium 1,4-and 2,6-Alkoxynaphthalenesulfonates. Journal of the American Oil Chemists' Society, 55(8): 625-628.

12. Mitchell, D. J., Tiddy, G. J. T., Waring, L., Bostock, T., \& Mcdonald, M. P. (1983). Phase Behaviour of Polyoxyethylene Surfactants with Water. Mesophase Structures and Partial Miscibility (Cloud Points). Journal of the Chemical Society, Faraday Transactions 1: Physical Chemistry in Condensed Phases, 79(4): 975-1000.

13. Roth, M., Lewit-Bentley, A., Michel, H., Deisenhofer, J., Huber, R., \& Oesterhelt, D. (1989). Detergent Structure in Crystals of a Bacterial Photosynthetic Reaction Centre. [10.1038/340659a0]. Nature, 340(6235): 659-662.

14. Pebay-Peyroula, E., Garavito, R. M., Rosenbusch, J. P., Zulauf, M., \& Timmins, P. A. (1995). Detergent Structure in Tetragonal Crystals of Ompf Porin. Structure, 3(10): 1051-1059.

15. Benz, R. (1988). Structure and Function of Porins from Gram-Negative Bacteria. Annual Review of Microbiology, 42(1): 359-393.

16. Sukumaran, S., Hauser, K., Maier, E., Benz, R., \& Mäntele, W. (2006). Structure-Function Correlation of Outer Membrane Protein Porin from Paracoccus Denitrificans. Biopolymers, 82(4): 344-348.

17. Caffrey, M. (2003). Membrane Protein Crystallization J. Struct. Biol., 142(1): 108-132.

18. Cherezov, V., Clogston, J., Papiz, M. Z., \& Caffrey, M. (2006). Room to Move: Crystallizing Membrane Proteins in Swollen Lipidic Mesophases J. Mol. Biol., 357(5): 1605-1618.

19. Faham, S., Boulting, G. L., Massey, E. A., Yohannan, S., Yang, D., \& Bowie, J. U. (2005). Crystallization of Bacteriorhodopsin from Bicelle Formulations at Room Temperature. Protein Sci, 14(3): 836-840.

20. Cho, H. S., Dominick, J. L., \& Spence, M. M. (2010). Lipid Domains in Bicelles Containing Unsaturated Lipids and Cholesterol. The Journal of Physical Chemistry B, 114(28): 9238-9245.

21. Diller, A., Loudet, C., Aussenac, F., Raffard, G., Fournier, S., Laguerre, M., et al. (2009). Bicelles: A Natural 'Molecular Goniometer' for Structural, Dynamical and Topological Studies of Molecules in Membranes. Biochimie, 91(6): 744-751.

22. Faham, S., \& Bowie, J. U. (2002). Bicelle Crystallization: A New Method for Crystallizing Membrane Proteins Yields a Monomeric Bacteriorhodopsin Structure. J. Mol. Biol., 316(1): 1-6. 
23. Van Dam, L., Karlsson, G., \& Edwards, K. (2004). Direct Observation and Characterization of Dmpc/Dhpc Aggregates under Conditions Relevant for Biological Solution Nmr. Biochimica et Biophysica Acta (BBA) - Biomembranes, 1664(2): 241-256.

24. Harroun, T. A., Koslowsky, M., Nieh, M. P., De Lannoy, C. F., Raghunathan, V. A., \& Katsaras, J. (2005). Comprehensive Examination of Mesophases Formed by Dmpc and Dhpc Mixtures. Langmuir, 21: 53565361.

25. Nieh, M.-P., Glinka, C. J., Krueger, S., Prosser, R. S., \& Katsaras, J. (2002). Sans Study on the Effect of Lanthanide Ions and Charged Lipids on the Morphology of Phospholipid Mixtures. Biophys. J., 82: 2487-2498.

26. Luecke, H., Schobert, B., Stagno, J., Imasheva, E. S., Wang, J. M., Balashov, S. P., et al. (2008). Crystallographic Structure of Xanthorhodopsin, the Light-Driven Proton Pump with a Dual Chromophore. Proceedings of the National Academy of Sciences, 105(43): 16561-16565.

27. Rasmussen, S. G. F., Choi, H.-J., Rosenbaum, D. M., Kobilka, T. S., Thian, F. S., Edwards, P. C., et al. (2007). Crystal Structure of the Human [Bgr]2 Adrenergic G-Protein-Coupled Receptor. [10.1038/nature06325]. Nature, 450(7168): 383-387.

28. Ujwal, R., Cascio, D., Colletier, J.-P., Faham, S., Zhang, J., Toro, L., et al. (2008). The Crystal Structure of Mouse Vdac1 at 2.3 لÖ Resolution Reveals Mechanistic Insights into Metabolite Gating. Proceedings of the National Academy of Sciences, 105(46): 17742-17747.

29. Vinothkumar, K. R. (2011). Structure of Rhomboid Protease in a Lipid Environment. Journal of Molecular Biology, 407(2): 232-247.

30. Kam, Z., Shore, H. B., \& Feher, G. (1978). On the Crystallization of Proteins. Journal of Molecular Biology, 123(4): 539-555.

31. Mcpherson, A. (Ed.). (1991). Useful Principles for the Crystallization of Proteins: CRC Press.

32. Faham, S., Ujwal, R., Abramson, J., \& Bowie, J. U. (2009). Chapter 5 Practical Aspects of Membrane

Proteins Crystallization in Bicelles. In D. Larry (Ed.), Current Topics in Membranes (Vol. Volume 63, pp. 109-125): Academic Press.

33. Nollert, P. (2004). Lipidic Cubic Phases as Matrices for Membrane Protein Crystallization. Methods: Macromolecular Crystallization, 34(3): 348-353.

34. Faham, S., \& Bowie, J. U. (2002). Bicelle Crystallization: A New Method for Crystallizing Membrane Proteins Yields a Monomeric Bacteriorhodopsin Structure. Journal of Molecular Biology, 316(1): 1-6. 35. Caffrey, M. (2003). Membrane Protein Crystallization. Journal of Structural Biology, 142(1): 108-132. 36. Lee, A. G. (2004). How Lipids Affect the Activities of Integral Membrane Proteins.

[10.1016/j.bbamem.2004.05.012]. Biochim Biophys Acta, 1666: 62-87.

37. Jacobson, K., Ishihara, A., \& Inman, R. (1987). Lateral Diffusion of Proteins in Membranes. Annual Review of Physiology, 49(1): 163-175.

38. Zhang, Y.-P., Lewis, R. N. a. H., \& Mcelhaney, R. N. (1997). Calorimetric and Spectroscopic Studies of the Thermotropic Phase Behavior of the N-Saturated 1,2-Diacylphosphatidylglycerols. Biophysical Journal, 72(2, Part 1): 779-793.

39. Cherezov, V., Clogston, J., Misquitta, Y., Abdel-Gawad, W., \& Caffrey, M. (2002). Membrane Protein Crystallization in Meso: Lipid Type-Tailoring of the Cubic Phase. Biophysical Journal, 83(6): 33933407.

40. Ujwal, R., \& Bowie, J. U. Crystallizing Membrane Proteins Using Lipidic Bicelles. Methods(0).

41. Kilic, M. S., Bazant, M. Z., \& Ajdari, A. (2007). Steric Effects in the Dynamics of Electrolytes at Large Applied Voltages. I. Double-Layer Charging. Physical Review E, 75(2): 021502.

42. Mclaughlin, S. (1989). The Electrostatic Properties of Membranes. Annual Review of Biophysics and Biophysical Chemistry, 18(1): 113-136.

43. Loosley-Millman, M. E., Rand, R. P., \& Parsegian, V. A. (1982). Effects of Monovalent Ion Binding and Screening on Measured Electrostatic Forces between Charged Phospholipid Bilayers. Biophysical Journal, 40(3): 221-232. 
44. Arnold, A., Labrot, T., Oda, R., \& Dufourc, E. J. (2002). Cation Modulation of Bicelle Size and Magnetic Alignment as Revealed by Solid-State Nmr and Electron Microscopy. Biophysical Journal, 83(5): 26672680.

45. Träuble, H., \& Eibl, H. (1974). Electrostatic Effects on Lipid Phase Transitions: Membrane Structure and Ionic Environment. Proceedings of the National Academy of Sciences, 71(1): 214-219.

46. Cunningham, B. A., Shimotake, J. E., Tamura-Lis, W., Mastran, T., Kwok, W. M., Kauffman, J. W., et al. (1986). The Influence of Ion Species on Phosphatidylcholine Bilayer Structure and Packing. Chemistry and Physics of Lipids, 39(1-2): 135-143.

47. Tatulian, S. A. (1983). Effect of Lipid Phase Transition on the Binding of Anions to Dimyristoylphosphatidylcholine Liposomes. Biochimica et Biophysica Acta (BBA) - Biomembranes, 736(2): 189-195.

48. Raffard, G., Steinbruckner, S., Arnold, A., Davis, J. H., \& Dufourc, E. J. (2000). Temperature-Composition Diagram of Dimyristoylphosphatidylcholine-Dicaproylphosphatidylcholine "Bicelles" Self-Orienting in the Magnetic Field. A Solid State 2h and 31p Nmr Study. Langmuir, 16(20): 7655-7662.

49. Afzal, S., Tesler, W. J., Blessing, S. K., Collins, J. M., \& Lis, L. J. (1984). Hydration Force between Phosphatidylcholine Surfaces in Aqueous Electrolyte Solutions. Journal of Colloid and Interface Science, 97(2): 303-307.

50. Inoko, Y., Yamaguchi, T., Furuya, K., \& Mitsui, T. (1975). Effects of Cations on Dipalmitoyl Phosphatidylcholine/Cholesterol/Water Systems. Biochimica et Biophysica Acta (BBA) - Biomembranes, 413(1): 24-32.

51. Lis, L. J., Lis, W. T., Parsegian, V. A., \& Rand, R. P. (1981). Adsorption of Divalent Cations to a Variety of Phosphatidylcholine Bilayers. Biochemistry, 20(7): 1771-1777.

52. Lis, L. J., Parsegian, V. A., \& Rand, R. P. (1981). Binding of Divalent Cations to Dipalmitoylphosphatidylcholine Bilayers and Its Effect on Bilayer Interaction. Biochemistry, 20(7): 1761-1770.

53. Tamura-Lis, W., Reber, E. J., Cunningham, B. A., Collins, J. M., \& Lis, L. J. (1986). Ca2+ Induced Phase Separations in Phospholipid Mixtures. Chemistry and Physics of Lipids, 39(1-2): 119-124.

54. Petrache, H. I., Tristram-Nagle, S., Harries, D., Kučerka, N., Nagle, J. F., \& Parsegian, V. A. (2006).

Swelling of Phospholipids by Monovalent Salt. Journal of Lipid Research, 47(2): 302-309.

55. Clarke, S. (1975). The Size and Detergent Binding of Membrane Proteins. J. Biol. Chem., 250(14): 54695469.

56. Ericsson, C. A., Soderman, O., Garamus, V. M., Bergstrom, M., \& Ulvenlund, S. (2005). Effects of Temperature, Salt, and Deuterium Oxide on the Self-Aggregation of Alkylglycosides in Dilute Solution. 2. N-Tetradecyl-Beta-D-Maltoside. Langmuir, 21: 1507-1515.

57. Ericsson, C. A., Soderman, O., Garamus, V. M., Bergstrom, M., \& Ulvenlund, S. (2004). Effects of Temperature, Salt, and Deuterium Oxide on the Self-Aggregation of Alkylglycosides in Dilute Solution. 1.N-Nonyl-Beta-D-Glucoside. Langmuir, 20: 1401-1408.

58. Giordano, R., Maisano, G., \& Teixeira, J. (1997). Sans Studies of Octyl-[Beta]-Glucoside and Glycine Micellar Solutions. J. Appl. Crystallography, 30(5(2)): 761-764.

59. Nilsson, F., \& Söderman, O. (1996). Physical-Chemical Properties of the N-Octyl B-D-Glucoside/Water System. A Phase Diagram, Self-Diffusion Nmr, and Saxs Study. Langmuir, 12(4): 902-908.

60. Angelov, B., Ollivon, M., \& Angelova, A. (1999). X-Ray Diffraction Study of the Effect of the Detergent Octyl Glucoside on the Structure of Lamellar and Nonlamellar Lipid/Water Phases of Use for Membrane Protein Reconstitution. Langmuir, 15(23): 8225-8234.

61. Lambert, O., Levy, D., Ranck, J.-L., Leblanc, G., \& Rigaud, J.-L. (1998). A New Gel-Like Phase in Dodecyl Maltosidelipid Mixtures: Implications in Solubilization and Reconstitution Studies. Biophys. J., 74(2): 918-930.

62. Vinson, P. K., Talmonand, Y., \& Walter, A. (1989). Vesicle-Micelle Transition of Phosphatidylcholine and Octyl Glucoside Elucidated by Cryo-Transmission Electron Microscopy. Biophys. J., 56(4): 669-681. 
63. Heerklotz, H., \& Seelig, J. (2000). Titration Calorimetry of Surfactant-Membrane Partitioning and Membrane Solubilization BBA - Biomembranes, 1508(1-2): 69-85.

64. Keller, M., Kerth, A., \& Blume, A. (1997). Thermodynamics of Interaction of Octyl Glucoside with Phosphatidylcholine Vesicles: Partitioning and Solubilization as Studied by High Sensitivity Titration Calorimetry. BBA - Biomembranes, 1326(2): 178-192.

65. Kimble-Hill, A. C., Singh, D., Laible, P. D., Hanson, D. K., Porcar, L., Butler, P., et al. (2009). Detergent Localization in Model Proteo-Bicelles. Biophys. J., 96(3): 453a.

66. Mouritsen, O. G., \& Bloom, M. (1984). Mattress Model of Lipid-Protein Interactions in Membranes. Biophys J, 46(2): 141-153.

67. Dumas, F., Sperotto, M. M., Lebrun, M.-C., Tocanne, J.-F., \& Mouritsen, O. G. (1997). Molecular Sorting of Lipids by Bacteriorhodopsin in Dlpc/Dspc Lipid Bilayers. Biophys J, 73(Oct): 1940-1953.

68. Bandyopadhyay, S., Shelley, J. C., \& Klein, M. L. (2001). Molecular Dynamics Study of the Effect of Surfactant on a Biomembrane. The Journal of Physical Chemistry B, 105(25): 5979-5986.

69. Carion-Taravella, B., Lesieur, S., Chopineau, J., Lesieur, P., \& Ollivon, M. (2001). Phase Behavior of Mixed Aqueous Dispersions of Dipalmitoylphosphatidylcholine and Dodecyl Glycosides: A Differential Scanning Calorimetry and X-Ray Diffraction Investigation. Langmuir, 18(2): 325-335.

70. Tilcock, C. P., \& Fisher, D. (1979). Interaction of Phospholipid Membranes with Poly(Ethylene Glycol)S. Biochim Biophys Acta, 577(1): 53-61.

71. Yamazaki, M., \& Ito, T. (1990). Deformation and Instability of Membrane Structure of Phospholipid Vesicles Caused by Osmophobic Association: Mechanical Stress Model for the Mechanism of Poly(Ethylene Glycol)-Induced Membrane Fusion. Biochemistry, 29(5): 1309-1314.

72. Kuhl, T., Guo, Y., Alderfer, J. L., Berman, A. D., Leckband, D., Israelachvili, J., et al. (1996). Direct Measurement of Polyethylene Glycol Induced Depletion Attraction between Lipid Bilayers. Langmuir, 12(12): 3003-3014.

73. Janiak, M. J., Small, D. M., \& Shipley, G. G. (1976). Nature of the Thermal Pretransition of Synthetic Phospholipids: Dimyristoyl- and Dipalmitoyllecithin. Biochemistry, 15(21): 4575-4580.

74. Boni, L. T., Stewart, T. P., Alderfer, J. L., \& Hui, S. W. (1981). Lipid-Polyethylene Glycol Interactions: Ii. Formation of Defects in Bilayers. Journal of Membrane Biology, 62(1): 71-77.

75. Boni, L. T., Stewart, T. P., \& Hui, S. W. (1984). Alterations in Phospholipid Polymorphism by Polyethylene Glycol. Journal of Membrane Biology, 80(1): 91-104.

76. Stewart, T. P., Hui, S. W., Portis Jr, A. R., \& Papahadjopoulos, D. (1979). Complex Phase Mixing of Phosphatidylcholine and Phosphatidylserine in Multilamellar Membrane Vesicles. Biochimica et Biophysica Acta (BBA) - Biomembranes, 556(1): 1-16.

77. De Planque, M. R. R., Greathouse, D. V., Koeppe, R. E., Schäfer, H., Marsh, D., \& Killian, J. A. (1998). Influence of Lipid/Peptide Hydrophobic Mismatch on the Thickness of Diacylphosphatidylcholine Bilayers. A $2 \mathrm{~h} \mathrm{Nmr}$ and Esr Study Using Designed Transmembrane A-Helical Peptides and Gramicidin a†. Biochemistry, 37(26): 9333-9345.

78. Hauser, H., Paltauf, F., \& Shipley, G. G. (1982). Structure and Thermotropic Behavior of Phosphatidylserine Bilayer Membranes. Biochemistry, 21(5): 1061-1067.

79. Helm, C. A., Tippmann-Krayer, P., Möhwald, H., Als-Nielsen, J., \& Kjaer, K. (1991). Phases of Phosphatidyl Ethanolamine Monolayers Studied by Synchrotron X-Ray Scattering. Biophysical Journal, 60(6): 1457-1476.

80. Johnson, S. J., Bayerl, T. M., Weihan, W., Noack, H., Penfold, J., Thomas, R. K., et al. (1991). Coupling of Spectrin and Polylysine to Phospholipid Monolayers Studied by Specular Reflection of Neutrons. Biophysical Journal, 60(5): 1017-1025.

81. Seelig, A., \& Seelig, J. (1977). Effect of a Single Cis Double Bond on the Structure of a Phospholipid Bilayer. Biochemistry, 16(1): 45-50.

82. Pink, D. A., \& Chapman, D. (1979). Protein-Lipid Interactions in Bilayer Membranes: A Lattice Model. PNAS, 76(4): 1542-1546. 
83. Lookman, T., Pink, D. A., Grundke, E. W., Deverteuil, F., \& Zuckermann, M. J. (1982). Phase Separation in Lipid Bilayers Containing Integral Proteins. Computer Simulation Studies. Biochem, 21(22): 5593-5601.

84. Macdonald, A. L., \& Pink, D. A. (1987). Thermodynamics of Glycophorin in Phospholipid Bilayer Membranes. Biochem, 26(7): 1909-1917.

85. Tessier-Lavigne, M., Boothroyd, A., Zuckermann, M. J., \& Pink, D. A. (1982). Lipid-Mediated Interactions between Intrinsic Molecules in Bilayer Membranes. J Chem Phys, 76(9): 4587-4599.

86. Tamm, I., \& Kikuchi, T. (1979). Early Termination of Heterogeneous Nuclear Rna Transcripts in Mammalian Cells: Accentuation by 5,6-Dichloro-1-\{Beta\} -D-Ribofuranosylbenzimidazole. PNAS, 76(11): 5750-5754.

87. Owicki, J. C., Springgate, M. W., \& Mcconnell, H. M. (1978). Theoretical Study of Protein-Lipid Interactions in Bilayer Membranes. PNAS, 75(4): 1616-1619.

88. Jahnig, F. (1981). Critical Effects from Lipid-Protein Interaction in Membranes. I. Theoretical Description. Biophys J, 36(2): 329-345.

89. Jahnig, F. (1981). Critical Effects from Lipid-Protein Interaction in Membranes. Ii. Interpretation of Experimental Results. Biophys J, 36(2): 347-357.

90. Jaehnig, F., Vogel, H., \& Best, L. (1982). Unifying Description of the Effect of Membrane Proteins on Lipid Order. Verification for the Melittin/Dimyristoylphosphatidylcholine System. Biochem, 21(26): 67906798.

91. Pink, D. A., Green, T. J., \& Chapman, D. (1980). Raman Scattering in Bilayers of Saturated Phosphatidylcholines. Experiment and Theory. Biochem, 19(2): 349-356.

92. Glaubitz, C., Grobner, G., \& Watts, A. (2000). Structural and Orientational Information of the Membrane Embedded M13 Coat Protein by 13c-Mas Nmr Spectroscopy. Biochimica et Biophysica Acta (BBA) Biomembranes, 1463(1): 151-161.

93. Sharpe, S., Barber, K. R., Grant, C. W. M., Goodyear, D., \& Morrow, M. R. (2002). Organization of Model Helical Peptides in Lipid Bilayers: Insight into the Behavior of Single-Span Protein Transmembrane Domains. Biophys J, 83(1): 345-358.

94. Killian, J. A. (1998). Hydrophobic Mismatch between Proteins and Lipids in Membranes. Biochimica et Biophysica Acta (BBA) - Reviews on Biomembranes, 1376(3): 401-415.

95. Van Der Wel, P. C. A., Strandberg, E., Killian, J. A., \& Koeppe, R. E., Ii. (2002). Geometry and Intrinsic Tilt of a Tryptophan-Anchored Transmembrane Alpha -Helix Determined by 2h Nmr. Biophys J, 83(3): 1479-1488.

96. Koehorst, R. B. M., Spruijt, R. B., Vergeldt, F. J., \& Hemminga, M. A. (2004). Lipid Bilayer Topology of the Transmembrane \{Alpha\}-Helix of M13 Major Coat Protein and Bilayer Polarity Profile by SiteDirected Fluorescence Spectroscopy. Biophys J, 87(3): 1445-1455.

97. Strandberg, E., Ozdirekcan, S., Rijkers, D. T. S., Van Der Wel, P. C. A., Koeppe, R. E., Ii, Liskamp, R. M. J., et al. (2004). Tilt Angles of Transmembrane Model Peptides in Oriented and Non-Oriented Lipid Bilayers as Determined by 2h Solid-State Nmr. Biophys J, 86(6): 3709-3721.

98. Liu, F., Lewis, R. N. a. H., Hodges, R. S., \& Mcelhaney, R. N. (2002). Effect of Variations in the Structure of a Polyleucine-Based \&\#X03b1;-Helical Transmembrane Peptide on Its Interaction with Phosphatidylcholine Bilayers. Biochem, 41(29): 9197-9207.

99. Needham, D., Mcintosh, T. J., \& Evans, E. (1988). Thermomechanical and Transition Properties of Dimyristoylphosphatidylcholine/Cholesterol Bilayers. Biochemistry, 27(13): 4668-4673.

100. Faham, S., Yang, D., Bare, E., Yohannan, S., Whitelegge, J. P., \& Bowie, J. U. (2004). Side-Chain Contributions to Membrane Protein Structure and Stability. Journal of Molecular Biology, 335(1): 297305.

101. Hite, R. K., Gonen, T., Harrison, S. C., \& Walz, T. (2008). Interactions of Lipids with Aquaporin-0 and Other Membrane Proteins. [10.1007/s00424-007-0353-9]. Pflugers Arch, 456: 651-661.

102. Hite, R. K., Li, Z., \& Walz, T. (2010). Principles of Membrane Protein Interactions with Annular Lipids Deduced from Aquaporin-0 2d Crystals. [10.1038/emboj.2010.68]. EMBO J, 29(10): 1652-1658. 
103. Faham, S. (2005). Crystallization of Bacteriorhodopsin from Bicelle Formulations at Room Temperature. [10.1110/ps.041167605]. Protein Sci., 14: 836-840.

104. Michel, H., \& Oesterhelt, D. (1980). Three-Dimensional Crystals of Membrane Proteins:

Bacteriorhodopsin. Proceedings of the National Academy of Sciences, 77(3): 1283-1285.

105. Takeda, K., Sato, H., Hino, T., Kono, M., Fukuda, K., Sakurai, I., et al. (1998). A Novel Three-

Dimensional Crystal of Bacteriorhodopsin Obtained by Successive Fusion of the Vesicular Assemblies. Journal of Molecular Biology, 283(2): 463-474.

106. Landau, E. M., \& Rosenbusch, J. P. (1996). Proc. Natl. Acad. Sci. U.S.A., 93: 14532.

107. Wang, H., Elferich, J., \& Gouaux, E. (2012). Structures of Leut in Bicelles Define Conformation and

Substrate Binding in a Membrane-Like Context. [10.1038/nsmb.2215]. Nat Struct Mol Biol, 19(2): 212219.

108. Payandeh, J., Scheuer, T., Zheng, N., \& Catterall, W. A. (2011). The Crystal Structure of a Voltage-Gated Sodium Channel. [10.1038/nature10238]. Nature, 475(7356): 353-358.

109. Bokoch, M. P., Zou, Y., Rasmussen, S. G. F., Liu, C. W., Nygaard, R., Rosenbaum, D. M., et al. (2010).

Ligand-Specific Regulation of the Extracellular Surface of a G-Protein-Coupled Receptor.

[10.1038/nature08650]. Nature, 463(7277): 108-112.

\section{Figure Legends}

Figure 1. Bicelle Mixture Phases. As the temperature and/or lipid concentration are increased, bicelles merge and form the nematic phase followed by the perforated lamellar phase. It has been shown that proteo-bicelle crystallization generally occurs in the perforated lamellar phase.

Figure 2. Bicelle structure response to AG content. Detergents such as OG and DM have been shown to change the phase and structure of lipids. As these detergents are added to the bicelle mixture, it elongates and thins the bicelle until the structure becomes that of the native AG micelle, being the most dominant component. This figure depicts that effect of rod shaped OG. 
Tables

Table 1. Bacteriorhodopsin Crystallization Conditions Reported in the Literature

\begin{tabular}{|c|c|c|c|c|c|c|c|}
\hline Temp & Additives & Amphiphile(s) & & $\begin{array}{l}\text { Protein } \\
\text { Conc. }\end{array}$ & $\begin{array}{l}\text { Growth } \\
\text { Period }\end{array}$ & $\begin{array}{l}\text { Crystal } \\
\text { Form, } \\
\text { Resolution }\end{array}$ & $\begin{array}{l}\text { Crystal } \\
\text { Packing }\end{array}$ \\
\hline $23^{\circ} \mathrm{C}$ & $\begin{array}{c}2.5 \mathrm{M} \\
\left(\mathrm{NH}_{4}\right)_{2} \mathrm{SO}_{4} \text { or } 2.8 \\
\mathrm{M} \mathrm{Na}_{2} \mathrm{SO}_{4} \\
\mathrm{pH} 4.8\end{array}$ & $\begin{array}{l}>1 \% \text { octyl } \\
\text { glucoside }\end{array}$ & micellar & $\begin{array}{c}\text { 30-35 } \\
\mathrm{nmol} / \mathrm{ml}\end{array}$ & $1 \mathrm{wk}$ & $\begin{array}{l}\text { NR, } \\
8 \AA\end{array}$ & $\begin{array}{l}\text { Type II } \\
(104)\end{array}$ \\
\hline $32^{\circ} \mathrm{C}$ & $\begin{array}{c}0.4-1.2 \mathrm{M} \\
\left(\mathrm{NH}_{4}\right)_{2} \mathrm{SO}_{4}, 0.16 \\
\mathrm{M} \mathrm{NaCl}, 0.04 \mathrm{M} \\
\text { sodium citrate } \\
(\mathrm{pH} 5.2) \text { and } \\
0.04 \% \mathrm{NaN}_{3}\end{array}$ & $\begin{array}{c}5 \mathrm{mg} / \mathrm{ml} \text { purple } \\
\text { membrane, } 2.5 \\
\mathrm{mg} / \mathrm{ml} \mathrm{OTG}\end{array}$ & $\begin{array}{c}\text { spherical } \\
\text { vesicles, } \\
\text { diameter }=50 \\
\mathrm{~nm}\end{array}$ & NR & $\begin{array}{l}1-2 \\
\text { wks }\end{array}$ & $\begin{array}{l}P 622, \\
3.5 \AA\end{array}$ & $\begin{array}{l}\text { Type I } \\
\text { (105) }\end{array}$ \\
\hline $20^{\circ} \mathrm{C}$ & $\begin{array}{c}0.7-4.0 \mathrm{M} \mathrm{Na} / \mathrm{K}- \\
\mathrm{P}_{\mathrm{i}} ; 1.5-3.75 \% \\
\text { methylpentanedi } \\
\text { ol; } 0.36-0.48 \% \\
\text { OG; final pH 5.6 }\end{array}$ & $\begin{array}{c}60-70 \%(\mathrm{wt} / \mathrm{wt}) \\
\text { monoolein or } \\
\text { mono-palmitolein }\end{array}$ & $\begin{array}{l}\text { bicontinuous } \\
\text { cubic phases }\end{array}$ & $\begin{array}{l}2.5-4.5 \\
\mathrm{mg} / \mathrm{ml}\end{array}$ & $\begin{array}{l}\text { Several } \\
\text { days }\end{array}$ & $\begin{array}{c}\mathrm{P6}_{3}, \\
3.7 \AA\end{array}$ & $\begin{array}{l}\text { Type I } \\
\text { (106) }\end{array}$ \\
\hline $37{ }^{\circ} \mathrm{C}$ & $\begin{array}{c}3.2 \mathrm{M} \mathrm{NaPO}_{4} \mathrm{pH} \\
3.5\end{array}$ & $\begin{array}{c}\text { 8\% Bicelle } \\
\text { DMPC:CHAPSO } \\
(2.8: 1), 0.7 \% \beta- \\
\text { octylglucoside } \\
\end{array}$ & $\begin{array}{l}\text { Perforated } \\
\text { lamellar }\end{array}$ & $8 \mathrm{mg} / \mathrm{ml}$ & 2 wks & $\begin{array}{l}\mathrm{P} 21, \\
2.0 \AA\end{array}$ & $\begin{array}{l}\text { Type I } \\
\text { (22) }\end{array}$ \\
\hline $25^{\circ} \mathrm{C}$ & $\begin{array}{c}100 \mathrm{mM} \\
\mathrm{HCOONa} \mathrm{pH} \\
4.3,28.5 \% \mathrm{PEG} \\
2 \mathrm{~K}, 280 \mathrm{mM} \\
\left(\mathrm{NH}_{4}\right)_{2} \mathrm{SO}_{4} \text {, and } \\
180 \mathrm{mM} \\
\text { hexanediol } \\
\end{array}$ & $\begin{array}{c}\text { 10\% Bicelle } \\
\text { DTPC:CHAPSO } \\
(3: 1)\end{array}$ & $\begin{array}{l}\text { Perforated } \\
\text { lamellar }\end{array}$ & $10 \mathrm{mg} / \mathrm{ml}$ & $2-3 \mathrm{mo}$ & $\begin{array}{l}\mathrm{P} 2{ }_{1} \\
1.8 \AA\end{array}$ & \multirow[t]{2}{*}{$\begin{array}{l}\text { Type I } \\
\text { (19) }\end{array}$} \\
\hline $25^{\circ} \mathrm{C}$ & $\begin{array}{c}2.45 \mathrm{M} \mathrm{NaH}_{2} \mathrm{PO}_{4} \\
\text { pH 3.7, } 180 \mathrm{mM} \\
\text { hexanediol, and } \\
3.5 \% \\
\text { triethyleneglycol }\end{array}$ & $\begin{array}{c}\text { 10\% Bicelle } \\
\text { DTPC:CHAPSO } \\
(2.8: 1)\end{array}$ & $\begin{array}{l}\text { Perforated } \\
\text { lamellar }\end{array}$ & $10 \mathrm{mg} / \mathrm{ml}$ & $\begin{array}{l}1-2 \\
\text { wks }\end{array}$ & $\begin{array}{l}\mathrm{C} 222_{1} \\
2.2 \AA\end{array}$ & \\
\hline
\end{tabular}


Table 2. Common Long Chain Phospholipids Used in Bicelles

\begin{tabular}{|c|c|c|}
\hline $\begin{array}{c}\text { Long Chain Lipid } \\
\text { (Carbons in acyl chain: } \\
\text { number unsaturated bonds) }\end{array}$ & $\begin{array}{c}\text { Melting } \\
\text { Temperature } \\
\text { (Celsius) }\end{array}$ \\
\hline DLPC (12:0) & 19.9 & -1 \\
\hline DTPC (13:0) & 22.5 & 14 \\
\hline DMPC (14:0) & 20.5 & 23 \\
\hline DMPG (14:0) & 22.4 & 35 \\
\hline DMPS (14:0) & 20.6 & 50 \\
\hline DMPE (14:0) & & 33 \\
\hline PC (15:0) & 25.4 & 41 \\
\hline DPPC (16:0) & 28.5 & 48 \\
\hline PC (17:0) & & 55 \\
\hline DSPC (18:0) & & 23 \\
\hline
\end{tabular}


Table 3. Phospholipid and Detergents

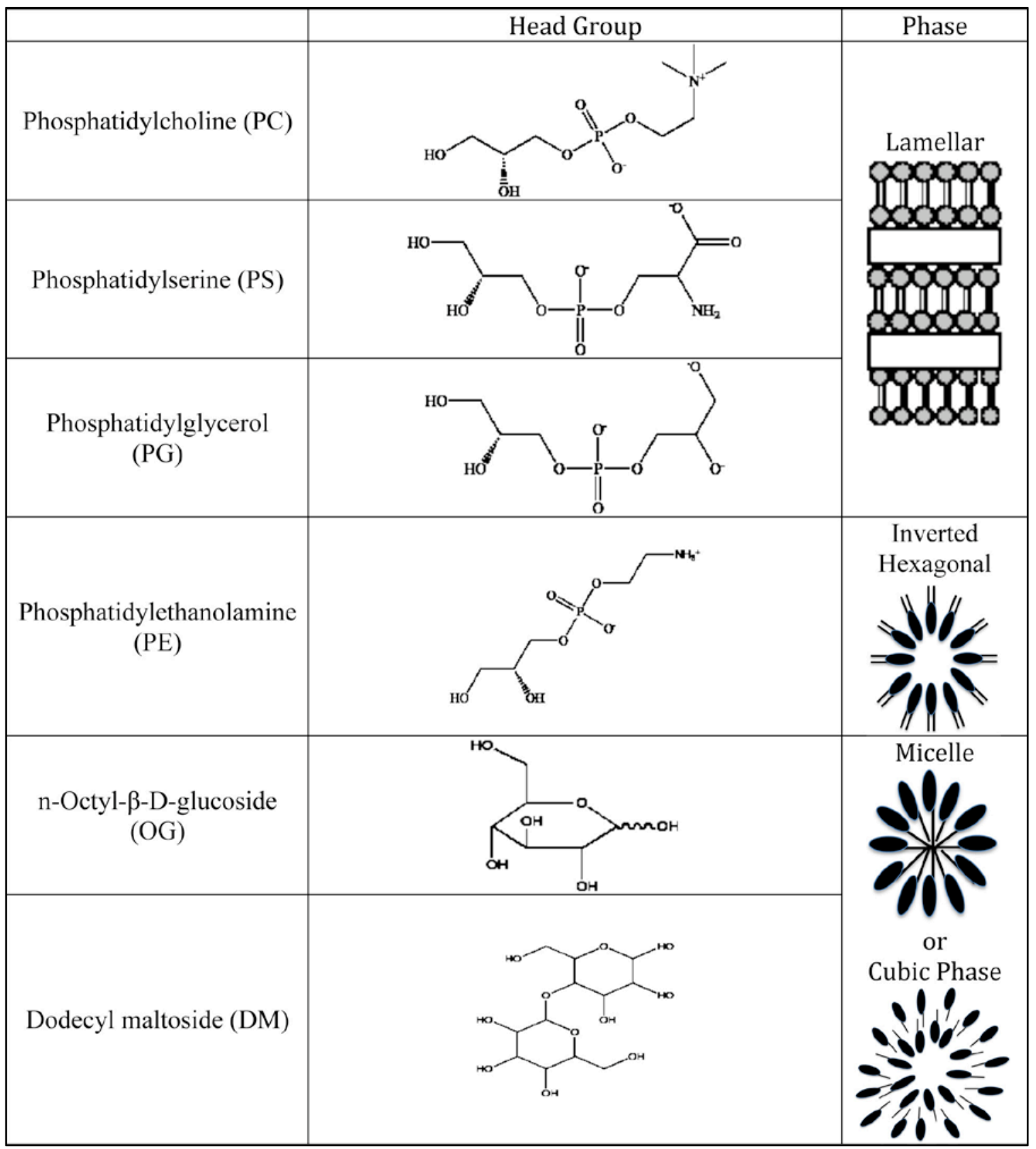


Table 4. Summary of Unique Structures in Bicelles Resolved by X-Ray Crystallography

\begin{tabular}{|c|c|c|c|c|}
\hline Protein & Bicelle Composition & Additives & Temp & $\begin{array}{l}\text { Crystal } \\
\text { Form, } \\
\text { Resolution }\end{array}$ \\
\hline $\begin{array}{l}\text { Bacteriorhodopsin } \\
\text { (22) }\end{array}$ & $\begin{array}{c}8 \% \\
\text { DMPC:CHAPSO } \\
(2.8: 1), 0.7 \% \beta- \\
\text { octylglucoside }\end{array}$ & $3.2 \mathrm{M} \mathrm{NaPO}_{4} \mathrm{pH} 3.5$ & $37 \circ \mathrm{C}$ & $\begin{array}{l}\mathrm{P} 21 \\
2.0 \AA\end{array}$ \\
\hline $\begin{array}{l}\text { LeuT-Leu } \\
\quad(107)\end{array}$ & $\begin{array}{c}7 \%(\mathrm{w} / \mathrm{v}) \\
\text { DMPC:CHAPSO } \\
(2.8: 1)\end{array}$ & $\begin{array}{c}100 \mathrm{mM} \text { sodium acetate, } \mathrm{pH} \\
\text { 4.5-5.0, 25-35\% (v/v) 2- } \\
\text { methyl-2,4-pentanediol (MPD) } \\
\text { and 5-10\% (v/v) PEG } 400\end{array}$ & $20^{\circ} \mathrm{C}$ & $\begin{array}{c}\mathrm{C} 2 \\
2.5 \AA\end{array}$ \\
\hline $\begin{array}{l}\text { NavAb voltage- } \\
\text { gated sodium } \\
\text { channel (108) }\end{array}$ & $\begin{array}{c}10 \% \\
\text { DTPC:CHAPSO (3:1) }\end{array}$ & $\begin{array}{c}1.8-2.1 \mathrm{M}\left(\mathrm{NH}_{4}\right)_{2} \mathrm{SO}_{4}, 100 \mathrm{mM} \\
\text { Na-citrate } \mathrm{pH} 4.75\end{array}$ & $25^{\circ} \mathrm{C}$ & $\begin{array}{l}\mathrm{I} 222, \\
2.7 \AA\end{array}$ \\
\hline $\begin{array}{c}\text { Methylated } \beta 2 \\
\text { Adrenergic } \\
\text { Receptor-Fab } \\
\text { complex } \\
\text { (109) }\end{array}$ & $\begin{array}{c}2 \% \text { w } / v \\
\text { DMPC:CHAPSO } \\
(3: 1)\end{array}$ & $\begin{array}{c}1.85-2.0 \mathrm{M}\left(\mathrm{NH}_{4}\right)_{2} \mathrm{SO}_{4}, \\
180 \mathrm{mM} \mathrm{C}_{2} \mathrm{H}_{3} \mathrm{NaO}_{2}, 5 \mathrm{mM} \\
\text { EDTA, } 100 \mathrm{mM} \mathrm{MES} \mathrm{or}^{-} \text {or } \\
\text { HEPES, pH 6.5-7.5 }\end{array}$ & $22^{\circ} \mathrm{C}$ & $\begin{array}{l}\mathrm{C} 2, \\
3.4 \AA\end{array}$ \\
\hline
\end{tabular}


Figures

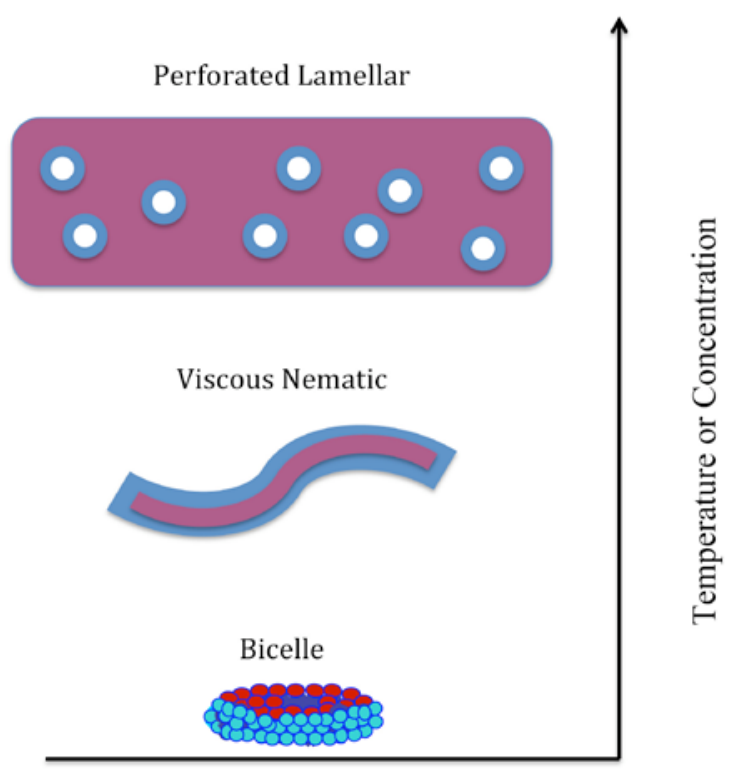

Figure 3. Bicelle Mixture Phases 


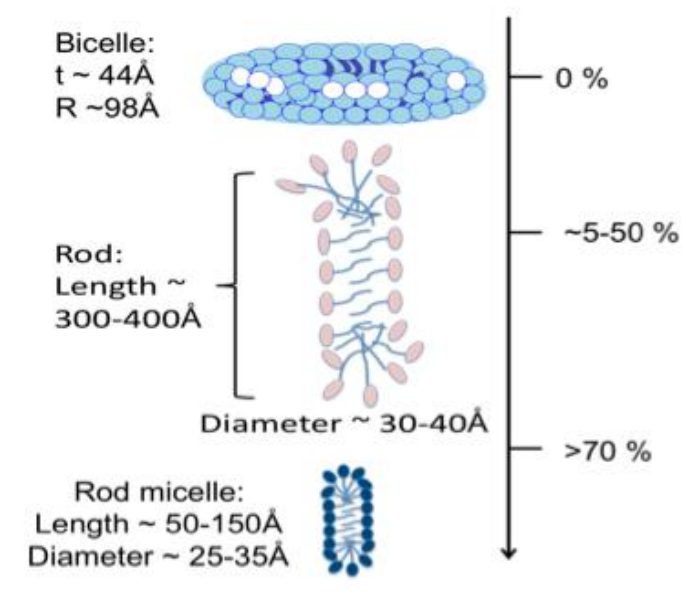

Figure 4. Bicelle structure response to AG content

\section{Supplemental Materials. N/A}

